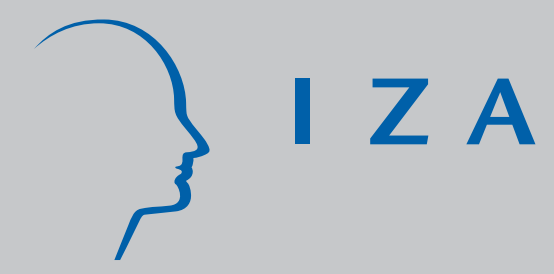

IZA DP No. 1918

Political Parties and Network Formation

Topi Miettinen

Panu Poutvaara

J anuary 2006 


\title{
Political Parties and Network Formation
}

\author{
Topi Miettinen \\ University College London \\ and University of Helsinki
}

Panu Poutvaara

University of Helsinki

and IZA Bonn

\section{Discussion Paper No. 1918 \\ January 2006}

IZA

P.O. Box 7240

53072 Bonn

Germany

Phone: +49-228-3894-0

Fax: +49-228-3894-180

Email: iza@iza.org

Any opinions expressed here are those of the author(s) and not those of the institute. Research disseminated by IZA may include views on policy, but the institute itself takes no institutional policy positions.

The Institute for the Study of Labor (IZA) in Bonn is a local and virtual international research center and a place of communication between science, politics and business. IZA is an independent nonprofit company supported by Deutsche Post World Net. The center is associated with the University of Bonn and offers a stimulating research environment through its research networks, research support, and visitors and doctoral programs. IZA engages in (i) original and internationally competitive research in all fields of labor economics, (ii) development of policy concepts, and (iii) dissemination of research results and concepts to the interested public.

IZA Discussion Papers often represent preliminary work and are circulated to encourage discussion. Citation of such a paper should account for its provisional character. A revised version may be available directly from the author. 
IZA Discussion Paper No. 1918

January 2006

\section{ABSTRACT}

\section{Political Parties and Network Formation*}

We argue that anti-corruption laws may provide an efficiency rationale for why political parties should meddle in the distribution of political nominations and government contracts. Anticorruption laws forbid trade in spoils that politicians distribute. However, citizens may pay for gaining access to politicians and, thereby, to become potential candidates for nominations. Such rent-seeking results in excessive network formation. Political parties may reduce wasteful network formation, thanks to their ability to enter into exclusive membership contracts. This holds even though anti-corruption laws also bind political parties.

JEL Classification: D72, D85, L14

Keywords: political parties, two-sided platforms, rent-seeking, network formation

Corresponding author:

Panu Poutvaara

Department of Economics

P.O. Box 17 (Arkadiankatu 7)

FIN-00014 University of Helsinki

Finland

Email: panu.poutvaara@helsinki.fi

\footnotetext{
* We thank for useful comments Essi Eerola, Henrik Jordahl, Katarina Keller, Klaus Kultti, Mikko Leppämäki, Mikael Priks, Olli Ropponen, Juuso Välimäki and the participants of the XVII Annual Meeting of Finnish Economists in Maarianhamina, PET 2005 in Marseille and seminar at HECER. The financial support of Yrjö Jahnsson Foundation is gratefully acknowledged.
} 


\section{Introduction}

Anti-corruption laws forbid trading attractive nominations made by politicians. But even though interested citizens are not able to buy such spoils, it pays off to be on good terms with the politicians. Citizens buy tickets to fund-raising events and spend time with politicians to be remembered when nominations are made. If there are no restrictions on to whom politicians can allocate jobs, citizens can gain by rubbing shoulders with several politicians. This is time-consuming both for citizens and for politicians and results in wasteful network formation. Here, political parties can provide valuable services.

Political parties are powerful gatekeepers in modern democracies. Citizens looking for positions of trust, and politicians allocating these, cannot belong to more than one party. As political parties can require their politician members to give the nominations to other party members, parties can reduce wasteful network formation between citizens and politicians. On the other hand, there is an additional linking cost when parties are present: parties also need to build links to politicians.

We compare network formation with and without the role of the political parties. We take as our starting point that political parties exist and that politicians distribute non-ideological spoils, such as nominations to positions of trust or hire civil servants who do not make political decisions. We ask whether the gatekeeping role of the political parties improves efficiency in the distribution of such spoils. We also ask who gains and who loses from the parties meddling in the network formation.

Our argumentation above suggests that party membership should be correlated with the value of the spoils that politicians distribute. Indeed, there is such a link: In Figure 1, we show how the share of voters belonging to a political party (in 1997 to 2000) is related to the total compensation costs for the public sector (as a percentage of GDP). ${ }^{1}$ If Austria is excluded ${ }^{2}$, the correlation between party membership and total compensation is 0.53 . A weaker but positive relationship holds for party membership and the GDP share of the public sector (taken from Statistics Finland 2005): without Austria, the correlation is 0.28. The case of Austria in itself also lends support to our analysis. In Austria, political parties are well represented in the public administration with many firms and organizations having traditionally double heads - one for the Social Democrats, one for the Conservatives. The strong politicization of nominations has been associated with exceptionally high level of party membership. (Encyclopedia of Austria (2005))

In our model, the party has full control of the network formation of its members. We focus on the networks used to allocate non-ideological spoils; for concreteness think of positions of trust in a municipality. In addition to providing exclusivity, political parties allocate each joining member to a unique politician belonging to the party. Political parties first pay politicians

\footnotetext{
${ }^{1}$ We include those European countries which where established democracies already before the fall of Communism, and for which data exists on both: Austria, Belgium, Denmark, Finland, France, Germany, Ireland, Italy, the Netherlands, Portugal, Spain, Sweden, Switzerland, and the United Kingdom. The data is from Mair and van Biezen (2001) and OECD (2001).

${ }^{2}$ Austria is an outlier: there 17.7 percent of voters belong to a political party, while the share in all other countries is between 1.6 and 9.7 percent. The R-Student Residual for Austria is 12.47, well above the 5 percent critical value of 1.96 .
} 


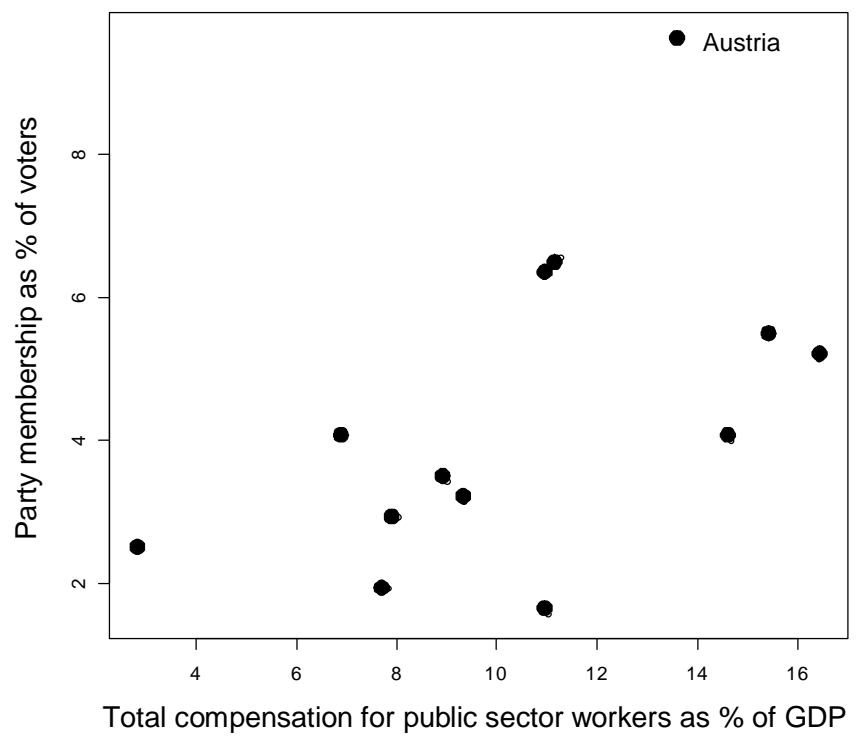

Figure 1: The size of the public sector and party membership

for joining and then sell links to politicians to rent-seeking citizens. ${ }^{3}$ In equilibrium, parties, politicians, and citizens have rational expectations about the network structure. Equilibrium prices are determined by these expectations and inter-party competition.

Also in the no-party equilibrium, expectations about the equilibrium network structure are rational. The equilibrium prices are determined by competition between politicians on the one side and citizens on the other side of the market. Given prices, politicians and citizens choose the number of links they sell and buy, respectively.

The more time citizens or politicians spend rubbing shoulders, the higher the opportunity cost of the time spent doing so. Thus, linking costs are convex and, in equilibrium, the prices of links are determined by marginal costs.

We first derive the equilibrium networking structure and the equilibrium payoffs in the no-party and in the party equilibrium. We show that a no-party equilibrium always exists and that the existence of a party equilibrium depends on the parameters of the model. Finally, we study the welfare properties of the equilibria. ${ }^{4}$

We find that the net effect of intermediaries on social surplus depends on networking costs, the value of lucrative nominations, and the relative numbers of politicians, citizens and parties. Therefore, a welfare-maximizing government may well find it optimal to promote the involvement of political parties in some cases, and actively discourage it in others.

Notice that allocating one rent-seeking citizen to each politician would minimize the cost

\footnotetext{
${ }^{3}$ Note that payments may take form of services, in addition to money.

${ }^{4}$ We refer only to the dimension of allocating the non-ideological spoils. Indeed, the role of the political parties in distributing positions of trust and governments jobs has varied both between countries and over time.
} 
of network formation. Hypothetically, parties have two ways of accomplishing this: either by selling upcoming nominations within the party or by allowing in only one citizen per each nominating politician. Yet, so as to the selling policy, anti-corruption laws bind also political parties. At the same time, pre-commitment not to accept additional members is prohibited since this would violate equal rights to political participation. ${ }^{5}$

We also find that politicians would be better off if political parties were not involved in the distribution of rents while citizens may gain from their presence, despite the fact that parties charge membership fees from citizens and transfer money to politicians! Even so, a party equilibrium may be incentive-compatible in that no single politician would find it optimal not to link with the party, provided that others do.

Our model has common features with several strands of literature. First, we suppose that for a citizen to receive a spoil from a politician, a connection must be established between the two. This relates the current paper to the literature on cooperative networks, pioneered by Jackson and Wolinsky (1996). However, in our model agents may trade in the right to control network formulation. This differentiates our model from Jackson and Wolinsky (1996) and the subsequent literature.

Second, in our model, the citizens compete for rents initiated by politicians as in rentseeking and lobbying contests literature (Tullock (1967, 1980), Bernheim and Whinston (1986), Baye, Kovenock and de Vries (1993), Grossman and Helpman (1994), Besley and Coate (2001) and Helpman and Persson (2001)). Yet, there are two major differences. In our model, links are costly for both citizens and politicians and endogenous, and require mutual consent. Payments are made in exchange for establishing links. In rent-seeking and lobbying literature, links are exogenous and costless, and payments are bids in an auction or in a contest. The only previous contribution that endogenizes the relationship between politicians and lobbyists is Felli and Merlo (2006). Our approach is complementary to theirs. Whereas they analyze ideological lobbying, we analyze lobbying on non-ideological spoils, like nominations and government contracts. Furthermore, Felli and Merlo (2006) assume that the links are costless. Throughout the analysis, we assume that anti-corruption laws work ${ }^{6}$. Therefore, we have implicitly in mind a modern democracy with relatively low level of corruption. Previous literature on contests has already analyzed extensively the case where anti-corruption laws can be circumvented.

Third, our model is related to two strands of intermediation literature, the middlemen literature (Rubinstein and Wolinsky (1987)) on the one hand, and the literature on two-sided markets (Rochet and Tirole (2003), Armstrong (2004)) on the other hand. In our model, the intermediaries, or the platforms, are the political parties. Our approach differs from these earlier contributions most importantly in that the intermediary plays a useful role by restricting the activity between the two sides of its market.

There are two features which separate politics and political parties from other areas of intermediation. The first one concerns the legal framework. Anti-corruption laws restrict the

\footnotetext{
${ }^{5}$ We could generate the motivation not to restrict network formation by assuming that some citizens want to join parties to seek for rents, while others for ideological reasons. Those joining parties for ideological reasons favor a no-restriction policy.

${ }^{6}$ The inability of politicians and citizens to trade nominations when these arise could result from outside monitoring or from there being a fraction of honest citizens and politicians who would report asking or offering bribes, provided that punishments for corruption are sufficiently high.
} 
ability of politicians and citizens to enter even into informal contracts on allocating projects in exchange of payments. In other areas of intermediation (like the market of goods and ideas) the two sides are typically allowed to enter into private contracts on the underlying goods or services, rather than just on linking together. The second difference is in the services that the intermediary provides. In previous literature, intermediaries are used only if they provide additional services in reducing search costs between the two sides of the market, information revelation of the underlying good or economizing transaction costs. We find that political parties need not provide any of these services; the service they provide is exclusivity - one cannot be a member of several political parties.

Fourth, our explanation complements previous efficiency rationales for the prominent role of political parties. For example, Alesina (1988) and Alesina and Spear (1988) find that political parties may reduce policy fluctuations, compared with the case in which subsequent cohorts of competing politicians with different preferences would engage in one-shot electoral competition. Caillaud and Tirole (2002) show that political parties may make up voters' information deficit by designing and endorsing electoral platforms. These previous contributions leave the puzzle of why intermediaries arise also in cases where they do not reduce the time spent searching, provide additional information, or solve various commitment problems. For example, it is questionable as to what extent a political party would provide new information when filling positions of trust or public jobs in a small municipality. Yet, even these positions and many other jobs are typically earmarked to different political parties. Our explanation for the role of a political party applies even in these cases.

The paper is organized as follows. Section 2 presents the model. Section 3 analyzes equilibrium payoffs and linking in the absence of parties, and section 4 in their presence. Section 5 explores whether politicians prefer a network with or without parties, and whether an eventual party equilibrium is incentive compatible. Section 6 presents a welfare comparison, and section 7 empirical evidence. Section 8 concludes.

\section{Model}

There are $n_{t}$ agents of type $t$, and there are three types $t \in\{A, B, C\}$. Type $A$ is called a politician, $i=1, \ldots, n_{A}$, type $B$ is called a citizen, $j=1, \ldots, n_{B}$ and type $C$ is called a party boss, $k=1, \ldots, n_{C}$. The politician receives a chance to distribute a project with probability $p .^{7}$

Each politician is indifferent to which citizen to give the project. Also, each citizen is indifferent as to which politician from whom she receives the project. Yet, for politician $i$ to be able to give the project to citizen $j$, there has to be a direct link between them. Party bosses can connect to citizens indirectly, through politicians, but they need direct links to politicians. Note that our framework allows analyzing politics at different levels. At the national level, party bosses would be leaders of the national parties. At the municipal level, they would be local leaders, and politicians could then be, for example, members of the municipal council. Whichever the level, politicians require having a direct access to their party boss. We take the

\footnotetext{
${ }^{7}$ All the results would remain the same also if the politician would receive a certain surplus, in case a project is fulfilled.
} 
identities of party bosses as exogenous ${ }^{8}$. Citizens can be interpreted as individuals interested in positions distributed by elected politicians or they can be interpreted as representatives of corporations interested in public projects, the allocation of which depends on decisions made by politicians.

The strength of a link between agents $a$ and $a^{\prime}$ is denoted $m_{a a^{\prime}}$. Obviously, the strength of the link from $a$ to $a^{\prime}$ must equal the strength of the link from $a^{\prime}$ to $a$, thus, $m_{a a^{\prime}}=m_{a^{\prime} a}$. There is an indirect link between $a$ and $a^{\prime}$, when there is a third agent $a^{\prime \prime}$ to whom both $a$ and $a^{\prime}$ are linked. We denote an indirect link between $a$ and $a^{\prime}$ by $\mu_{a a^{\prime}}$. Maintaining a direct link requires time, and may require other costs. A decreasing marginal productivity in other activities, or an increasing marginal utility of leisure, implies that the marginal cost of time spent on networking is increasing. Furthermore, networking with competing agents simultaneously may pose additional challenges. For example, a politician who seeks to extract contributions from competing contractors may need to spend more time in convincing these of the benefits of giving. To capture these features, we model the marginal costs of networking as increasing. A cost for $i$ of maintaining a total amount $m$ of links is

$$
\frac{1}{2} \mathrm{~cm}^{2}
$$

where $c$ is a positive linking cost parameter independent of a player's type.

The total amount of links in a network without political parties need not be an integer. Formally, the width of each link is between zero and one, zero implying no link at all and one implying a complete link. The width of a link can be thought to be proportional to the time spent in maintaining the link. The probability weight that each link receives when a politician allocates projects to citizens is proportional to the width of the link.

The width of potential links with political parties, on the other hand, is restricted to be either zero or one. This reflects the differences between the formal relationships with political parties and the informal relationships between citizens and politicians. We assume that the number of agents is sufficiently large that citizens never find it attractive to maintain full links to all politicians.

\section{$3 \quad$ Networks without Political Parties}

Assume that there are more citizens than politicians, $0<n_{A}<n_{B}$. In this section, we assume that the political parties do not participate in the network formation between politicians and citizens looking for projects distributed by politicians. There are $\gamma$ times more citizens than politicians, $n_{B}=\gamma n_{A}, \gamma \in\{2,3, \ldots\} .{ }^{9}$ If there are several citizens linked to a politician, we assume that the politician allocates the project randomly, so that the probability that each citizen is chosen is proportional to the width of the link. Thus the probability of getting the

\footnotetext{
${ }^{8}$ In a richer framework, we could model overlapping generations of politicians, with all young politicians being of type A and one of the old politicians becoming the party boss in the second.

${ }^{9}$ This simplification allows us to solve the model explicitly. Otherwise, the model would have to be solved numerically.
} 
project from politician $i$ equals

$$
p \frac{m_{j i}}{\sum_{\beta=1, \ldots, n_{B}} m_{\beta i}} .
$$

Citizens are able to pay politicians for networking even if the citizens cannot pay for the projects. For example, citizens interested in nominations can give campaign contributions to candidates or volunteer their time. Explicitly requiring a politician to assign a nomination in exchange for such contribution, on the other hand, would be considered bribing and not lobbying.

A citizen has to pay politician $i$ a reward, $r_{i}$, for maintaining a full link. If the link is only partial, then the reward is reduced proportionally. Note that this is a gross price, and it has to compensate the politician for her marginal cost of linking. In addition to paying politicians $r_{i}$ for maintaining the links, citizens have to pay their own linking costs.

The expected payoff of a citizen $j$ reads $^{10}$

$$
\sum_{i} p \frac{m_{j i}}{\sum_{\beta=1, \ldots, n_{B}} m_{\beta i}} s-\sum_{i} m_{j i} r_{i}-\frac{c}{2}\left(\sum_{i} m_{j i}\right)^{2} .
$$

The politician $i$ 's maximization problem is as follows

$$
\max _{m_{i 1}, \ldots, m_{i n_{B}}}\left\{\sum_{j} m_{i j} r_{i}-\frac{c}{2}\left(\sum_{j} m_{i j}\right)^{2}\right\}
$$

resulting in first order conditions

$$
r_{i}-c\left(\sum_{j} m_{i j}\right)=0
$$

for $j=1, \ldots, n_{B}$. We assume that each citizen acts atomistically ${ }^{11}$ taking as given the reward, $r_{i}$, and the total amount of links that each politician has to citizens, $m_{i B}$, and maximizes

$$
\max _{m_{j 1}, \ldots, m_{j n_{A}}}\left\{\sum_{i} p \frac{m_{j i}}{m_{i B}} s-\sum_{i} m_{j i} r_{i}-\frac{c}{2}\left(\sum_{i} m_{j i}\right)^{2}\right\}
$$

Thus, the first order conditions write

$$
\frac{p s}{m_{i B}}-r_{i}-c \sum_{i} m_{j i}=0
$$

for $i=1, \ldots, n_{A}$.

It is easy to see that each politician is indifferent so as to which citizens are linked to her. She only cares about the aggregate amount of links to citizens, $m_{i B}$. Also, as long as linking

\footnotetext{
${ }^{10}$ This formulation coincides with Tullock (1980) with $R=1$. Yet, the decision variable is not the cost of effort, but rather, the number of links and the cost of linking is not linear but convex in the number of links.

${ }^{11}$ The appendix shows how the equilibrium derived here corresponds to an equilibrium of a dynamic game. Notice that the atomisticity implies that, in the party equilibrium of section 4, there is no strategic own-side membership externality effect (see Rochet and Tirole, 2004) even if such an effect is non-strategically present in our model.
} 
rewards and the aggregate amount of links, $m_{i B}$, are equal across politicians, each citizen is indifferent so as to how to allocate the links between politicians. All that matters is her aggregate amount of links, $m_{j A}$. Since linking cost functions are convex and identical across politicians and citizens, the number of links is equal across politicians, on the one hand, and across citizens, on the other hand. Equilibrium rewards are equal to the politicians' marginal linking cost. Thus, citizens equate their own marginal linking cost and the equilibrium reward, $c \sum_{j=1}^{n_{A}} m_{j i}+r_{B A}^{N}$, to the expected rent from linking, $\frac{p s}{m_{A B}^{N}}$, where $m_{A B}^{N}$ is the total amount of links in the equilibrium from a politician to citizens and $r_{B A}^{N}$ is the equilibrium reward. Furthermore, we denote by $m_{B A}^{N}$ the total amount of links that a citizen has to politicians in equilibrium.

This allows us to derive the no-party equilibrium ${ }^{12}$. We summarize it as proposition 1:

Proposition 1 In the no-party equilibrium, the total supply of links by each politician is

$$
m_{A B}^{N}=\sqrt{\frac{\gamma p s}{(\gamma+1) c}}
$$

the total demand for links by each citizen is

$$
m_{B A}^{N}=\sqrt{\frac{p s}{\gamma(\gamma+1) c}} ;
$$

and the reward for links from citizen to politician is

$$
r^{N}=\sqrt{\frac{c \gamma p s}{(\gamma+1)}}
$$

Proof. See appendix.

It is now straightforward to calculate the equilibrium surpluses. These are summarized in proposition 2:

Proposition 2 The equilibrium payoff for the politician is

$$
\pi_{A}^{N}=\frac{\gamma p s}{2(\gamma+1)}
$$

which is increasing in $p, s$ and $\gamma$.

The expected equilibrium payoff for the citizen is

$$
\pi_{B}^{N}=\frac{p s}{2 \gamma(\gamma+1)}
$$

which is increasing in $p$ and $s$ and decreasing in $\gamma$.

\footnotetext{
${ }^{12}$ We use the superscript $N$ for the equilibrium values of endogenous variables in the no-party equilibrium. Similarly, superscript $P$ is used for the party equilibrium in section 4 .
} 
Proof. The equilibrium payoffs follow from plugging the equilibrium demand, supply and reward of the previous proof into the payoff functions.

The politician benefits from the scarcity of politicians, whereas the opposite holds for the citizen. As the number of citizens per politician increases, the demand of links of each citizen decreases but the demand per politician increases. Thus, due to marginal cost pricing and convex costs, the profit of the politician increases. Yet, for the citizen the strength of the link per each politician decreases and, thus, so does the probability of getting the project. Yet, the reward that needs to be paid is higher. Hence, the payoff for the citizen decreases.

Surprisingly, the cost parameter of maintaining links enters neither the politician's surplus nor that of the citizen ${ }^{13}$. This implies that the efficiency gains due to the reduction of the cost of maintaining the links are wasted in additional network formation.

Notice that for any parameter values of the model the total amount of links in the equilibrium is positive and both the citizen and the politician receive a positive surplus. This implies the following proposition that establishes the existence of a no-party equilibrium.

Proposition 3 For any feasible parameter values of the model, there exists a no-party equilibrium.

\section{Networks with Political Parties}

In this section, we introduce political parties as intermediaries that join together politicians and citizens. The service that the parties provide turns out to be the exclusivity of links: no politician or citizen can link to a member of another party. This reduces the wasteful multiplication of links to each politician. Yet, there are costs to this as well, since each politician must now link to the political party in addition to the citizens.

A party boss, whose type is denoted by $C$, exerts control rights over his party (or its local unit in the municipality interpretation). He maximizes the party's surplus, net of his own linking costs. ${ }^{14}$ Assume that there are $\phi$ politicians per each party boss, where $\phi \in\{2,3, \ldots\}$ Therefore, $n_{A}=\phi n_{C}$ and as $n_{B}=\gamma n_{A}, n_{B}=\gamma \phi n_{C}$. We make the following assumptions:

Assumption 1. The party boss receives the right to control and design the network of all the politicians and citizens linked with him on the condition that the party bears all the linking costs. ${ }^{15}$

Assumption 2. Political parties, represented by party bosses, sign exclusive contracts that state that citizens linked to them are not able to sign up with other political parties. The political parties cannot commit not to sign contracts with additional politicians and citizens.

\footnotetext{
${ }^{13}$ This result is not in the core of our analysis. It may be due to the functional forms and may not be robust to other specifications.

${ }^{14}$ We do not take a stance whether party bosses would keep the surplus, or part of it, for private consumption, or if they use the surplus for ideological purposes.

${ }^{15}$ If the party would not bear the linking costs, then the party boss would have an incentive to require politicians to build more links ex post than they have agreed on ex ante.
} 
Assumption 3. When citizens make their linking decisions, they know how many politicians belong to each party.

Assumption 4. Keeping up the links between politicians and citizens requires effort or resources, like in the case with no political parties. Also, links between party bosses and politicians require maintaining.

Assumption 5. The party bosses play the active role, making take-it-or-leave-it offers to the politicians and citizens.

Assumption 6. There must be a direct link between the politician and the citizen who carries out the project initiated by the politician.

\subsection{Properties of Party Equilibrium}

In this subsection, we focus on an equilibrium where all politicians and citizens are party members - every politician and citizen has a direct or an indirect link to a party. In the next subsection, we establish conditions for the existence of such an equilibrium when each politician and each citizen must collect a non-negative payoff for joining a party. This provides an individual rationality condition with a zero outside option. A positive payoff outside option for the politician is considered in section 5.2. There we study whether a politician has an incentive not to join a party and link to citizens without the control of the party. ${ }^{16}$

For notational simplicity, the number of links that an agent of type $t$ has to $t^{\prime}$ types is denoted by the same variable for all agents of the same type. This is restrictive in general but, as in the no-party equilibrium, it turns out to be a property of any equilibrium: all agents of the same type have an equal number of links and pay and receive equal payments. There will be no direct payments between politicians and citizens since the party regulates all links. ${ }^{17}$ Yet, by assumption 6 , the structure of the network within a party always includes direct links between politicians and citizens.

We denote the reward that each citizen pays to the party boss by $r_{B C}$ and the reward that each politician gets from the party boss by $r_{C A}$. A payment is made independently of the type of the link but the cost of a link is born only from direct links. We show in the next subsection that both $r_{B C}$ and $r_{C A}$ are positive when the individual rationality constraints are satisfied.

\footnotetext{
${ }^{16}$ We do not consider equilibria in which the value of the project is so low that not all citizens are willing to link to a party even if all politicians are party members.

${ }^{17}$ Note that citizens often pay the party in the form of volunteer work. Our framework could be generalized to allow for this, without changing the qualitative results. Then the interpretation would be the following. Each citizen pays to the party in the form of work up to the point in which the marginal cost for citizen equals the marginal benefit for the party. The difference between the monetarized value of this efficient work effort and the equilibrium payment is settled in money. Party bosses may then let citizens (or part of them) work directly for the politician, thus transferring part of the compensation in kind to the politician.
} 
The party's profits are

$$
\begin{aligned}
\pi_{C}\left(m_{C A}, m_{C B}\right)= & \left(m_{C B}+\mu_{C B}\right)\left[r_{B C}-\frac{c}{2}\left(m_{B A}+m_{B C}\right)^{2}\right] \\
& -\left(m_{C A}+\mu_{C A}\right)\left[r_{C A}+\frac{c}{2}\left(m_{A B}+m_{A C}\right)^{2}\right] \\
& -\frac{c}{2}\left(m_{C A}+m_{C B}\right)^{2} .
\end{aligned}
$$

The first term is the sum of rewards paid by the citizens to the party net of the citizens' linking costs paid by the party. The second term comprises the rewards to politicians and their linking costs paid by the party. The third term consists of the party's own linking costs.

By assumption, there must be a direct link between the politician and the citizen who carries out the project. This being the case, the optimal structure of the network is such that the party boss is directly linked to the politicians and each politician is linked directly to citizens. There are no direct links between the party boss and the citizens. Thus, (7) reduces to

$$
\begin{aligned}
\pi_{C}\left(m_{C A}, m_{C B}\right)= & \mu_{C B}\left[r_{B C}-\frac{c}{2}\right] \\
& -m_{C A}\left[r_{C A}+\frac{c}{2}\left(m_{A B}+1\right)^{2}\right] \\
& -\frac{c}{2}\left(m_{C A}\right)^{2} .
\end{aligned}
$$

Equally, the citizen's expected payoff is

$$
\pi_{B}=p_{B} s-r_{B C}
$$

The probability that a given link results in a project is

$$
p_{B}=p \frac{m_{C A}}{m_{C B}} .
$$

Finally, a politician linked to a party receives a surplus equalling

$$
\pi_{A}=r_{C A} .
$$

In the party equilibrium, each citizen and each politician is linked to a party. The next propositions 4 to 6 characterize the party equilibria

Proposition 4 In any party equilibrium, each party boss is linked to $\phi$ politicians and $\phi \gamma$ citizens. The number of direct links are $m_{A B}^{P}=\gamma, m_{B A}^{P}=1, m_{A C}^{P}=1, m_{C A}^{P}=\phi, m_{B C}^{P}=0=m_{C B}^{P}$.

Proof. In the appendix.

In addition, we can derive the equilibrium rewards paid by the party and the citizen and the equilibrium probability that a citizen gets the project. 
Proposition 5 In any party equilibrium, each party pays a reward for each politician

$$
r_{C A}^{P}=\frac{c\left(\gamma^{2}+\gamma-2 \phi-2\right)}{2}
$$

and each citizen pays the party a reward

$$
r_{B C}^{P}=c(\gamma+2)
$$

for the right to link to a politician. The equilibrium probability of getting the project is

$$
p_{B}^{P}=\frac{p}{\gamma}
$$

Proof. In the appendix.

The equilibrium network structure is based on two principles. First, the party is forced to build direct links between the citizens and the politicians. This being the case, it is less costly to the party boss to build his own links to the citizens via a politician rather than directly. Moreover, allocating an equal number of citizens to each politician minimizes the cost of linking.

Second, competition drives the benefit from an additional link equal to its marginal cost. Having a unique market reward and unequal number of links would violate the condition of zero marginal net benefit. The one with less links could apply the cheapest network structure described above and get the same reward with a lower marginal cost. Hence, the number of links for any two agents of the same kind in the market must be the same. The rewards are such that the parties are indifferent between selling an additional link to a citizen, or buying an additional link to a politician, and sticking to the equilibrium number of links.

Due to the marginal cost pricing and the fact that each politician is allocated an equal number of citizens, the reward paid by the citizen to the party, (10), increases in $\gamma$, the number of citizens per politician, and in $c$, the linking cost parameter.

Again, due to marginal cost pricing, the reward that a party pays to the politician equals the rewards from $\gamma$ citizens linked to the marginal politician, less the marginal politician's costs of linking to the $\gamma$ citizens and the linking cost of those citizens to the politician, less the party's marginal cost of linking to the politicians. The surplus per politician, $\gamma r_{B C}^{P}-$ $\frac{c}{2}(\gamma+1)^{2}-\gamma \frac{c}{2}$, increases in $\gamma$ and in $c$. On the other hand, the party's marginal cost of linking to the politicians increases in $c$ and $\phi$ since each party links to $\phi$ politicians in equilibrium. Hence, the equilibrium reward to politician decreases in $\phi$ and increases in $\gamma$. As both the gross surplus per politician and the marginal cost of linking to politicians increase in $c$, its net effect on the reward that political parties pay politicians is uncertain, a priori.

Next, we characterize the equilibrium payoffs.

Proposition 6 In any party equilibrium, the equilibrium payoffs are

$$
\begin{gathered}
\pi_{C}^{P}=\frac{c \phi(\phi+1)}{2} \\
\pi_{A}^{P}=\frac{c}{2}\left(\gamma^{2}+\gamma-2 \phi-2\right) \\
\pi_{B}^{P}=\frac{p s}{\gamma}-c(\gamma+2) .
\end{gathered}
$$


Proof. These follow from inserting the equilibrium demands and rewards into the surplus expressions.

The comparative statics of these equilibrium payoffs are straightforward:

Proposition 7 The comparative statics of the equilibrium payoffs are

$$
\begin{aligned}
\frac{\partial \pi_{C}^{P}}{\partial c} & >0, \frac{\partial \pi_{C}^{P}}{\partial \phi}>0 \\
\frac{\partial \pi_{A}^{P}}{\partial c} & >0, \frac{\partial \pi_{A}^{P}}{\partial \phi}<0, \frac{\partial \pi_{A}^{P}}{\partial \gamma}>0 \\
\frac{\partial \pi_{B}^{P}}{\partial c} & <0, \frac{\partial \pi_{B}^{P}}{\partial \gamma}<0 .
\end{aligned}
$$

The following corollary identifies cases where the citizen's party equilibrium payoff is higher than her no-party equilibrium payoff:

Corollary 1 The citizen's party equilibrium payoff is higher than her no-party equilibrium payoff if

$$
\frac{p s}{c} \geq \frac{2(\gamma+2)(\gamma+1) \gamma}{(2 \gamma+1)}
$$

Above we found two countervailing effects of the linking cost $c$ on the party's equilibrium payoff: the gross surplus per politician increases in $c$ and the marginal linking cost to politicians increases in $c$. Proposition 7 shows that the gross surplus per politician effect always dominates.

Proposition 7 reveals a conflict of interest among the agents concerning the cost parameter. Whereas politicians and political parties actually prefer a higher cost of networking, citizens prefer a lower one. That politicians and parties benefit from an increasing transaction cost follows from competition between politicians. When selling links to the citizens, the political parties charge a reward, $r_{B C}^{P}$, equal to the marginal cost of adding one additional link. A lower value of the cost parameter would result in lower rewards and thus in lower equilibrium payoffs to the parties and politicians. ${ }^{18}$

\subsection{Existence with Individual Rationality Constraints}

Let us now assume that each politician and citizen can refrain from joining a party, in which case they would receive a payoff of zero. The condition for the existence of a party equilibrium is then characterized in proposition 8 :

Proposition 8 There is a party equilibrium with $\pi_{A}^{P} \geq 0$ and $\pi_{A}^{P} \geq 0$ where each citizen and each politician links to a unique party if and only if

$$
\frac{p s}{c} \geq \gamma(\gamma+2) \geq 2 \phi+2+\gamma
$$

\footnotetext{
${ }^{18}$ This suggests that parties and politicians might object to technological innovations that might reduce the costs of networking - such as political participation via the internet.
} 
that is if and only if the number of citizens per politician is not too small or too large, the linking cost and the number of politicians per party boss is sufficiently small, and the expected rent is sufficiently large.

Proof. These results follow from the assumption that $r_{C A} \geq 0$ and from the requirement that $\pi_{B}^{P} \geq 0$.

The positive payoff constraints create bounds for the number of citizens per politician. The condition $\gamma^{2}+\gamma \geq 2 \phi+2$ is a requirement that when a politician links with a party, the reward that the party pays to the politician

$$
r_{C A}^{P}=\frac{c\left(\gamma^{2}+\gamma-2 \phi-2\right)}{2},
$$

is not negative. This holds as long as the number of citizens per politician is sufficiently high relative to the number of politicians per party. A positive reward is in line with what we observe in politics: political parties typically pay their politicians in the form of campaign contributions etc. rather than the other way round, and members pay parties membership fees rather than parties paying members.

The equilibrium payoff of the citizen, (13), is non-negative if and only if the first inequality in (15) holds. Increasing the number of citizens per politician sufficiently makes a citizen's expected surplus negative.

Combining the positive payoff conditions with (14), we notice that it is possible that the citizen prefers the no-party equilibrium to the party equilibrium or vice versa. Another point of interest, which we report as a corollary to proposition 8 is that, in the party equilibrium, the number of citizens per politician is smaller whenever the party equilibrium exists.

Corollary 2 If the party equilibrium exists, then the number of citizens linked to each politician is smaller in the party equilibrium than in the no-party equilibrium.

Proof. In the appendix.

As in the economy as a whole, also in each party, there are $\gamma$ times more citizens than politicians by proposition 4 . Thus, if the party let its politicians and citizens freely interact with the only restriction that none of its politicians or citizens could interact with non-members, the equilibrium payoffs would not be affected vis-à-vis the no-party equilibrium. Yet, the party enforces the network design within the party so that each citizen is linked to one politician only. The total amount of links per politician $\gamma$ in the party-equilibrium is always smaller than the total amount of links per politician in the no-party-equilibrium, $\sqrt{\frac{\gamma p s}{(\gamma+1) c}}$.

\section{$5 \quad$ Preference for Party Membership}

In the equilibrium derived above, the party provides link exclusivity and network design services for the citizens and the politicians. The individual rationality constraints guarantee that each politician and each citizen rather links to the party than remains inactive. Yet, on the one hand, we do not know whether the politicians prefer the no-party equilibrium to the party 
equilibrium. If they did, they might be able to make a collective binding decision not to link with any political parties and gain. On the other hand, given that all the other politicians are linked to a party, each politician might prefer not to link with a party and build up her own network instead. We call a party equilibrium where the politician's payoff is higher than the outside option of staying out of any party and creating own network instead an incentive compatible party equilibrium.

In this section, we study whether the politicians prefer to link directly to citizens. We first study the profitability of a coordinated and collective shift by the politicians from the party equilibrium to the no-party equilibrium. Second, we study the profitability of a unilateral deviation of a single politician from linking with a party to linking with citizens directly when all other politicians remain linked with the political parties. Notice that if a deviation by a single politician from the party equilibrium pays off but a collective deviation does not, then, from politicians' perspective, the structure is similar to that of a prisoner's dilemma. We show first that politicians always prefer the no-party equilibrium to the party equilibrium, and second that with some parameter values, a deviation by a single politician pays off whereas with others it does not. Thus, a dilemma structure never arises.

\subsection{Politicians' Preferences Concerning the Equilibria}

We next identify which of the equilibria is the politicians' preferred equilibrium. Politicians prefer the no-party equilibrium to the party equilibrium if the surplus in the former, (5), is greater than the surplus in the latter, (12). Hence, the condition that each politician prefers the no-party equilibrium is

$$
\frac{\gamma p s}{2(\gamma+1)} \geq \frac{c}{2}\left(\gamma^{2}+\gamma-2 \phi-2\right)
$$

When (17) holds, the no-party equilibrium is preferred by the politicians. The next proposition shows that the politicians prefer the no-party equilibrium.

Proposition 9 The politicians prefer the no-party equilibrium.

Proof. In the appendix.

This result is not surprising in the light of corollary 2. The total amount of links per politician $\gamma$ in the party-equilibrium is always smaller than the total amount of links per

politician in the no-party-equilibrium, $\sqrt{\frac{\gamma p s}{(\gamma+1) c}}$. But, when competing for the politicians, the parties pay politicians a reward equalling the marginal benefit of that politician to the party which on the other hand is just $\gamma$ times the profit that it makes per citizen that becomes a member of the party. This latter, on the other hand, is smaller than what the politician makes per citizen in the no-party equilibrium since, as shown above, the total amount of links per politician is smaller in the party-equilibrium.

\subsection{Incentive Compatible Party Equilibrium}

If a politician cannot be prevented from not linking with a party and linking with citizens directly, the equilibrium surplus for a politician has to be greater than or equal to the surplus 
of the politician linking directly with citizens. Studying a politician's incentives to remain linked with a party when all other politicians are linked with a party is the focus of this subsection. We assume that a deviating politician is able to make take-it-or-leave-it reward offers to citizens potentially willing to link. The politician is unable to commit not to sell additional links. Therefore, she sells links until an additional link would give her a negative payoff. This determines the number of citizens that will link to the politician. In equilibrium, the citizens anticipate the total amount of links that a deviating politician would like to sell. We show that there are cases where the politician prefers to deviate and others where she does not.

Proposition 10 There are feasible parameter values for which the party equilibrium is incentive compatible and others for which it is not.

Proof. The proof is in the appendix.

\section{Welfare}

The aggregate surplus in the no-party equilibrium, defined as $W^{N}$, equals

$$
W^{N}=n_{A} p s-n_{B} \frac{1}{2} \frac{p s}{\gamma(\gamma+1)}-n_{A} \frac{1}{2} \frac{\gamma p s}{(\gamma+1)} .
$$

In the party equilibrium, the aggregate surplus $W^{P}$ equals

$$
W^{P}=n_{A} p s-n_{A} \frac{c}{2}(\gamma+1)^{2}-n_{B} \frac{c}{2}-n_{C} \frac{c}{2} \phi^{2} .
$$

The next proposition gives a necessary and a sufficient condition for the party equilibrium to create a larger surplus:

Proposition $11 W^{P} \geq W^{N}$ if and only if $\gamma^{2}+3 \gamma+\phi+1 \leq \frac{p s}{c}$.

Proof. In the appendix.

When (i) the number of politicians per party, $\phi$, (ii) the number of citizens per politician, $\gamma$, and (iii) the linking costs, $c$, are sufficiently small vis-à-vis the citizen's expected share of the project, $p s$, then the intermediation is socially preferred.

Note that we have cases when the party equilibrium creates a smaller surplus even if it exists and cases where the party equilibrium creates a larger surplus and, yet, the market agents may coordinate the no-party equilibrium. To see this, suppose that the second inequality in the existence condition for the party equilibrium, (15) holds, that is $\gamma(\gamma+2) \geq 2 \phi+2+\gamma$. This can be achieved, for instance, by setting $\gamma \geq \phi=2$. The first inequality in (15) sets a lower bound for $\frac{p s}{c}$. This inequality is far less stringent than the condition of proposition 11. When the latter holds, so does the lower bound for $\frac{p s}{c}$ in (15). Thus, if we choose a large enough $\frac{p s}{c}$, the party equilibrium exists and generates a larger surplus than the no party equilibrium. Yet, when we choose $\frac{p s}{c}$ such that $2 \phi+2+\gamma \leq \gamma(\gamma+2) \leq \frac{p s}{c}<\gamma^{2}+3 \gamma+\phi+1$, the party equilibrium exists but generates a lower surplus than the no-party equilibrium. Thus, depending on the 
parameter values of the model, intervention may be needed in order to enforce the no-party equilibrium or the party equilibrium depending on the parameter values of the model.

The politicians prefer the no-party equilibrium, and they have an incentive to bring about institutions to guarantee its emergence. Sometimes, the interest of the social planner coincides with the interest of the politicians and promoting the emergence of such institutions may be in the planner's interest. Yet, when the party equilibrium is preferable, the social planner should make every effort to prevent the emergence of such institutions. Furthermore, even the politician's individual incentives may render the party equilibrium unstable for instance if the linking costs are sufficiently low.

\section{Empirical Evidence}

Our framework suggests that the value of belonging to a political party is increasing in the value of rents distributed by politicians to citizens. Our simple model assumed that potential party members are identical. With heterogeneous citizens, a member's valuation of belonging to a party should translate into different levels of party membership, rather than just to different membership fees, costs and personal investments. If the chance to be nominated to a post by a politician of the party is an important motivation to join political parties, then the number of citizens willing to pay the costs for joining should be increasing in the total value of these nominations. ${ }^{19}$ The latter can be approximated by the GDP share of total compensation to public sector workers. Similarly, if citizens join to seek rents distributed through government contracts then the public expenditures share of GDP should be positively related to party membership.

As reported in the introduction, there is a strong correlation between the share of voters belonging to a political party and the total compensation costs for the public sector employees as a percentage of GDP. The following series of regressions confirms this: Table 1 has four regressions for the countries in Figure 1, excluding Austria. ${ }^{20}$ In the first regression, we use the total compensation costs for the public sector (as a percentage of GDP) as an explanatory variable for the share of voters belonging to a political party. The effect is statistically significant at the 10 percent level. In the second regression, we control for the effect of population size. This is intended to capture the possibility that citizens may be politically more active in small countries for reasons outside our model, like greater proximity in smaller communities. In the third regression, we use as an additional control the logarithm of GDP per capita evaluated at the purchasing power parity. This acts as a control for different levels of economic

\footnotetext{
${ }^{19}$ As an important part of the costs of and fees for belonging to a party are non-monetary, like providing voluntary work, it is not possible to test our model simply by studying membership fees in different countries.

${ }^{20}$ Data from Mair and van Biezen (2001), OECD (2001), OECD (2005) and Statistics Finland (2005).
} 
development. In the fourth regression, we control for both at the same time.

TABLE 1. Explaining party membership.

\begin{tabular}{lllll}
\hline \multicolumn{4}{l}{ Dependent variable: share of voters belonging to a political party $(\mathrm{N}=13)$} \\
\hline Intercept & 1.073 & 12.156 & -38.521 & -16.971 \\
& $(1.677)$ & $(6.569)^{*}$ & $(44.318)$ & $(43.803)$ \\
Compensation costs (as \% of GDP) & 0.311 & 0.163 & 0.353 & 0.204 \\
& $(0.150)^{*}$ & $(0.162)$ & $(0.158)^{* *}$ & $(0.177)$ \\
Log of population & & -0.989 & & -0.912 \\
& & $(0.565)$ & & $(0.590)$ \\
Log of GDP per capita (PPP) & & & 3.897 & 2.790 \\
& & & $(4.358)$ & $(4.146)$ \\
Adjusted $R^{2}$ & 0.217 & 0.361 & 0.203 & 0.300 \\
p-value & 0.062 & 0.051 & 0.130 & 0.107 \\
\hline
\end{tabular}

Notes: Standard error in parentheses. ${ }^{*}\left({ }^{* *}\right)$ denotes significance at the $10 \%(5 \%)$ level.

Given the small number of countries, our results should be interpreted as suggestive, rather than as strict tests of the theory. Nonetheless, our findings lend some support to our model. Party membership is positively related to the value of rents that politicians distribute, as measured by the compensation costs of public sector workers relative to GDP. This relationship is weaker, but does not disappear, when additional controls are used. Moreover, we run the regressions using the GDP share of public expenditures indicating the extent of politically distributed rents, rather than just compensation costs relative to GDP. The results turned out qualitatively similar, but with statistically weaker effects.

\section{Conclusion}

In this paper, we suggest a novel explanation for the role of political parties: party politicians only distribute rents to other party members, thus cancelling out the incentive of non-members to seek rents and spend resources in constructing links to the parties' politicians. This reduces link formation and enables the party to create value for the party members. Indeed, our empirical analysis suggests that party membership is more common in countries with a bigger public sector. To differentiate the role of public employment from general income redistribution, we focused on the compensation costs of the public sector employees as percentage of GDP.

We take as our starting point anti-corruption laws which forbid citizens from paying politicians directly for nominations or publicly commissioned projects. These laws still allow citizens (or firms) to pay for gaining access to politicians, for example by buying tickets to fund-raising events, volunteering, and making campaign contributions. Competition for politicians' attention results in wasteful network formation, which political parties may alleviate, when citizens can belong to only one party. Political parties can reduce network formation costs by attaching each party member to a given politician, rather than allowing them to build links to several politicians. Similarly, political parties require politicians to give projects to their party's members. 
It should be highlighted that anti-corruption laws also restrict the activities of political parties. They are not allowed to trade in nominations or projects directly, but only to receive membership payments and allocate funds to politicians' campaigns. Even political parties are unable to fully eliminate wasteful network formation, as they cannot commit to restricting the number of members. ${ }^{21}$

Even though political parties may save network formation costs, they need not. There are two reasons for this result which may at first glance appear counterintuitive. First, the use of political parties typically necessitates more formal network structure (there are only two degrees of strengths of the link, either there is a link or there is not). Politicians and citizens, on the other hand, may have more informal links with varying degrees of strength of the link. Second, maintaining links to the political parties is costly. When parties are present, the network must cover the parties in addition to politicians and citizens, creating a need for additional links.

The use of political parties improves welfare whenever the linking costs, the number of politicians per party boss and the number of citizens per politician are sufficiently low and the expected rent for the citizen is sufficiently large. Yet, when the number of citizens per politician or the number of politicians per party boss is high, but not too high to prevent the party equilibrium from emerging, the no-party equilibrium is socially preferred.

We also find that politicians would be better off without political parties while citizens may gain from their presence, despite the fact that parties charge membership fees from citizens and transfer money to politicians. This surprising result arises as payments by citizens might be even higher without parties. Even so, a party equilibrium may be incentive-compatible in that no single politician would find it optimal to deviate from it, provided that others do not. If a party equilibrium results in higher welfare, the problem of the social planner is to prevent the emergence of politicians' collective bodies that would guarantee the coordination of the no-party equilibrium. If the party equilibrium results in higher welfare and is not incentivecompatible, then the society may change this by increasing the costs of individual politicians to deviate from it. This may explain, for example, why public money to political campaigns is often channelled through political parties, rather than directly to politicians.

Our framework raises several topics for further research. First, we could endogenize the identity of politicians in the citizen-candidate tradition pioneered by Osborne and Slivinski (1996) and Besley and Coate (1997). Second, we could endogenize the identity of party bosses by presenting an overlapping generations framework in which party bosses arise from senior politicians. Finally, Persson and Tabellini (2003) show that electoral rules have significant consequences on the organization of political parties and on economic policy. To what extent do these differences arise through the role that political parties play in network formation?

\footnotetext{
${ }^{21}$ Allowing political parties to pre-commit not to take additional members would disenfranchise those citizens not belonging to the selected few from fully participating in the political life.
} 


\section{Appendix}

\subsection{Foundation for the atomistic approach}

We suppose that in the no-party equilibrium, citizens and politicians decide their optimal demands given the market price and in addition citizens do not take into account the effect of their demand on the total amount of links of the politician. In this appendix, we give a game theoretic foundation for this approach.

We suppose that the links are created before the politician's term of office or the election. We let the effective strength of the link, $m_{j i}^{e}$, be a function not only of the strength, $m_{i j}$, but also of the timing of the creation of the link. It is more likely that the project is given to someone whom the politician has known for a longer time. If the finite but continuous time interval during which links are built is normalized to one, let $\delta_{i j}$ be the fraction of time that elapses before a link between $i$ and $j$ is created. Then the effective strength of the link is $m_{j i}^{e}=m_{i j}\left(1-\delta_{i j}\right)$.

If politicians post take-it or leave-it rewards at each point in time and the pairwise strengths of the links are settled based on the posted rewards, the emerging market equilibrium would correspond to the static equilibrium of section 3 .

\subsection{Proof of proposition 1}

Proof. If all agents of the same type behave identically in aggregate demands and supplies in equilibrium, the supply of links equals the number of agents times the total amount of links that each agent forms,

$$
S_{m}=n_{A} m_{A B}^{N} .
$$

On the other hand, the demand for links equals,

$$
D_{m}=n_{B} m_{B A}^{N}
$$

In equilibrium, the supply of links by agents of type $A$ has to equal demand by agents of type $B$

$$
n_{A} m_{A B}^{N}=n_{B} m_{B A}^{N} .
$$

Thus, acting atomistically, the probability that a citizen gets a project when she acquires a link of width $m_{i A}$ is $p_{B}^{N} m_{i A}$ where

$$
p_{B}^{N}=\frac{p n_{A}}{n_{A} m_{A B}^{N}}=\frac{p}{m_{A B}^{N}}
$$

is taken as given. Thus we can sum up the first order conditions and write the citizen's first order condition as

$$
p_{B}^{N} s-r_{B A}^{N}-c m_{B A}^{N}=0 .
$$

In a similar manner, we can sum up the politician's first order conditions to get

$$
r_{B A}^{N}-c m_{A B}^{N}=0
$$


Inserting (20), (21) and (23) into (22) gives

$$
\frac{p}{m_{A B}^{N}} s-c m_{A B}^{N}-c \frac{n_{A} m_{A B}^{N}}{n_{B}}=0 .
$$

Inserting $n_{B}=\gamma n_{A}$ gives

$$
\frac{p}{m_{A B}^{N}} s-c m_{A B}^{N}-c \frac{m_{A B}^{N}}{\gamma}=0 .
$$

Hence, in equilibrium, a politician's supply of links equals

$$
m_{A B}^{N}=\sqrt{\frac{\gamma p s}{(\gamma+1) c}} .
$$

From (20), we can solve a citizen's equilibrium demand for links,

$$
m_{B A}^{N}=\sqrt{\frac{p s}{\gamma(\gamma+1) c}} .
$$

Therefore, by (23), the equilibrium reward for the link is

$$
r^{N}=\sqrt{\frac{c \gamma p s}{(\gamma+1)}} .
$$

\subsection{Proof of proposition 4}

Proof. 1) Let us first assume that each party has $\gamma$ citizens for each politician linked to it. The equilibrium reward must be such that the party is indifferent on whether to sell one additional link or not. Selling one additional link would increase the linking costs of the politician to whom the citizen would be linked from $\frac{c}{2}(\gamma+1)^{2}$ to $\frac{c}{2}(\gamma+2)^{2}$. In addition, the party would have to pay $\frac{c}{2}$ for the new citizen's linking cost as we assume that the party bears all linking costs. The marginal increase in the linking costs then equals $\frac{c}{2}(2 \gamma+4)=c(\gamma+2)$. For any party, the net gain that a party would derive from selling a link to one more citizen cannot be positive, since then it would provide an incentive to deviate and sell a link to an additional citizen. Hence, $r_{B C}^{P} \leq c(\gamma+2)$. On the other hand, it is not possible that the net gain is negative, $r_{B C}^{P}<c(\gamma+2)$, since then each party could increase the reward that a citizen has to pay up to $c(\gamma+2)$. This is because for every party $r_{B C}^{P} \leq c(\gamma+2)$ and hence no party strictly prefers offering a link to an additional citizen and the citizen cannot do anything but remain with her party even with the higher reward. Thus,

$$
r_{B C}^{P}=c(\gamma+2)
$$

2) Let us now show that given that each party has $m_{C A}$ politicians, the equilibrium number of citizens is $m_{C A} \gamma$. Suppose that there are two political parties, $C^{\prime}$ and $C^{\prime \prime}$ and that the number of citizens linked to the two political parties are such that $\frac{\mu_{C B}^{\prime \prime}}{m_{C A}^{\prime \prime}}<\frac{\mu_{C B}^{\prime}}{m_{C A}^{\prime}}$. Then, since all citizens 
and politicians are linked and $n_{B}=\gamma n_{A}=\gamma \phi n_{C}$, we can choose two political parties so that $\frac{\mu_{C B}^{\prime \prime}}{m_{C A}^{\prime \prime}}<\gamma<\frac{\mu_{C B}^{\prime}}{m_{C A}^{\prime}}$. But then using the cheapest structure described in point (1) of the proof, for all politicians linked to $C^{\prime \prime}$ the number of links $m^{\prime \prime}$ is smaller than or equal to $\gamma+1$. Yet, for the party $C^{\prime}$ there must be a politician for whom the number of links $m^{\prime \prime}$ is strictly greater than $\gamma+1$. Hence,

$$
\frac{c}{2}\left(m^{\prime \prime}+1\right) \leq \frac{c}{2}(\gamma+1)<\frac{c}{2}\left(m^{\prime}+1\right) .
$$

The reward $r_{B C}^{\prime}$ of the party $C^{\prime}$ must be higher than or equal to $\left(2 m^{\prime}+2\right)$. Otherwise, the last additional link does not provide positive profit. But for $C^{\prime \prime}$ the marginal cost is lower and therefore,

$$
r_{B C}^{\prime} \geq c\left(m^{\prime}+2\right)>c\left(m^{\prime \prime}+2\right) .
$$

Thus, party $C^{\prime \prime}$ makes a profit by selling a cheaper additional link to a customer of $C^{\prime}$ and the customer has a higher or equal probability of getting the project with $C^{\prime \prime}$ than with $C^{\prime}$ and this cannot be an equilibrium. We have a contradiction. Hence, $\frac{\mu_{C B}^{\prime \prime}}{m_{C A}^{\prime \prime}}=\frac{\mu_{C B}^{\prime}}{m_{C A}^{\prime}}=\gamma$.

3) Let us now show that the equilibrium reward $r_{C A}$ satisfies

$$
r_{C A}^{P}=\frac{c\left(\gamma^{2}+\gamma-1\right)}{2}-\frac{c}{2}\left(2 m_{C A}^{P}+1\right) .
$$

The benefits to the party are the payments from all citizens linked to the politicians, $m_{C A}^{P} \gamma r_{B C}^{P}$. The costs include the payment made to the politicians $m_{C A}^{P} r_{C A}^{P}$, the linking costs of politicians paid by political parties, $m_{C A}^{P} \frac{c}{2}(\gamma+1)^{2}$, the linking costs of the citizens linked to the politicians of the party, $m_{C A}^{P} \gamma \frac{c}{2}$, and the party's own linking costs to the politicians $\frac{c}{2}\left(m_{C A}^{P}\right)^{2}$. In equilibrium, the marginal benefit from linking to politicians must equal its marginal cost, that is

$$
\gamma r_{B C}^{P}=\frac{c}{2} \gamma+r_{C A}^{P}+\frac{c}{2}(\gamma+1)^{2}+\frac{c\left(2 m_{C A}^{P}+1\right)}{2} .
$$

Substituting from (27), the payment $r_{C A}^{P}$ is given by (29).

4) Let us now show that any network structure where for some party, $m_{C A} \neq \phi$, cannot be an equilibrium. Suppose that there are two political parties $C^{\prime \prime}$ and $C^{\prime}$ with $m_{C A}^{\prime}<m_{C A}^{\prime \prime}$. Then the party $C^{\prime \prime}$ is not willing to pay more than $r_{C A}^{\prime \prime}=\frac{c\left(\gamma^{2}+\gamma-1\right)}{2}-\frac{c}{2}\left(2 m_{C A}^{\prime \prime}+1\right)$ to the politicians linked to it. Otherwise, the last additional politician would deteriorate the payoff of $C^{\prime \prime}$. But $C^{\prime}$ can buy a politician customer of $C^{\prime \prime}$ with a positive profit, since

$$
r_{C^{\prime \prime} A}^{P} \leq \frac{c\left(\gamma^{2}+\gamma-1\right)}{2}-\frac{c}{2}\left(2 m_{C A}^{\prime \prime}+1\right)<\frac{c\left(\gamma^{2}+\gamma-1\right)}{2}-\frac{c}{2}\left(2 m_{C A}^{\prime}+1\right)
$$

and $C^{\prime}$ can afford paying $r_{C^{\prime \prime} A}^{P}+\varepsilon$ for a sufficiently small $\varepsilon>0$. Hence, $m_{C A} \neq \phi$ cannot be an equilibrium.

\subsection{Proof of proposition 5}

Proof. The equilibrium reward $r_{B C}^{P}$ is given by equation (27) in part 1) of the proof of proposition 4. The equilibrium reward,

$$
r_{C A}^{P}=\frac{c}{2}\left(\gamma^{2}+\gamma-2 \phi-2\right),
$$


now follows from substituting $r_{B C}^{P}$ and $m_{C A}^{P}=\phi$ into (30) in the proof of proposition 4 and rearranging. By inserting $m_{C A}^{P}$ and $m_{C B}^{P}$ in equation (8), we obtain the equilibrium probability of receiving the project

$$
p_{B}^{P}=p \frac{\phi}{\phi \gamma}=\frac{p}{\gamma}
$$

\subsection{Proof of corollary 2}

Proof. By proposition 4, the number of citizens per politician in the party equilibrium equals $\gamma$. By proposition 1, the number of citizens per politician in the no-party equilibrium is $\sqrt{\frac{\gamma p s}{(\gamma+1) c}}$. Thus, the claim amounts to

$$
\gamma<\sqrt{\frac{\gamma p s}{(\gamma+1) c}}
$$

which is equivalent to

$$
\gamma(\gamma+1)<\frac{p s}{c}
$$

This condition holds if the party equilibrium exists by proposition 8 .

\subsection{Proof of proposition 9}

Proof. The condition for politicians to have higher total surplus with political parties than without is

$$
\frac{c}{2}\left(\gamma^{2}+\gamma-2 \phi-2\right) \geq \frac{\gamma p s}{2(\gamma+1)}
$$

We can rewrite $(32)$ as

$$
\frac{p s}{c} \leq \gamma^{2}+\gamma+\gamma+1-2 \phi-2-\frac{2 \phi+2}{\gamma}
$$

As we simultaneously have the participation constraint for citizens of $\gamma(\gamma+2) \leq \frac{p s}{c}$, political parties prefer a feasible network structure with political parties to a situation without political parties if

$$
\gamma(\gamma+2) \leq \frac{p s}{c} \leq \gamma^{2}+2 \gamma+1-2 \phi-2-\frac{2 \phi+2}{\gamma}
$$

For this inequality to hold, it must be that

$$
-1-2 \phi-\frac{2 \phi+2}{\gamma} \geq 0
$$

This is a contradiction. Therefore, the party equilibrium is not preferred by the politicians. 


\subsection{Proof of proposition 10}

Proof. Suppose that $\sqrt{\frac{p s}{c}+1}-1$ is a positive integer. Let us assume that the links built by the deviating politician $S$ have to be full links. $S$ acts as a monopoly with respect to citizens, making them take-it-or-leave it offers of building links. Citizens correctly anticipate the number of links $n$ that $S$ is going to sell.

Anticipating that the number of links that $\mathrm{S}$ sells is $n$, a citizen who is offered a link is willing to pay up to $r$ satisfying

$$
\frac{p s}{n}=r+\frac{c}{2}(1+1)^{2}-\frac{c}{2},
$$

which simplifies to $\frac{p s}{n}=r+\frac{3 c}{2}$.

The politician's surplus writes

$$
r n-\frac{c n^{2}}{2}
$$

which is increasing in $r$ for a given $n$ and increasing in $n$ if for a given $r, r>\frac{c}{2}(2 n+1)$. Thus, the optimum condition satisfies

$$
\begin{aligned}
& r=\frac{p s}{n}-\frac{3 c}{2} \\
& r \leq \frac{c}{2}(2 n+1) .
\end{aligned}
$$

We assume that parameters $p, s$, and $c$ are such that $n=\sqrt{\frac{p s}{c}+1}-1$ is an integer. However, it is easy to check that $\sqrt{\frac{p s}{c}+1}-1$ is a solution to $\frac{c}{2}(2 n+1)=\frac{p s}{n}-\frac{3 c}{2}$. Thus the optimal $r$ and $n$ are $r^{*}=\frac{p s}{\sqrt{\frac{p s}{c}+1}-1}-\frac{3 c}{2}$ and $n^{*}=\sqrt{\frac{p s}{c}+1}-1$.

Therefore, the surplus for $\mathrm{S}$ satisfies

$$
r^{*} n^{*}-\frac{c\left(n^{*}\right)^{2}}{2}=\frac{c}{2}\left(\frac{p s}{c}+1-\sqrt{\frac{p s}{c}+1}\right) .
$$

Denote $\frac{p s}{c}=x$. The incentive compatibility condition is satisfied if and only if the politician's party equilibrium payoff is greater than or equal to the payoff of not remaining linked to a party, that is

$$
\frac{c}{2}(x+1-\sqrt{x+1}) \leq \frac{c}{2}\left(\gamma^{2}+\gamma-2 \phi-2\right) .
$$

This is equivalent to

$$
\left(x+1-\left(\gamma^{2}+\gamma-2 \phi-2\right)\right) \leq \sqrt{x+1} .
$$

In this expression, both sides are positive since $x \geq \gamma^{2}+\gamma-2 \phi-2$. Otherwise, citizens would not be willing to buy links in a party equilibrium. By squaring both sides of (34) and rearranging we obtain

$$
\left[(x+1)-\left(\gamma^{2}+\gamma-2 \phi-2\right)\right]\left[x-\left(\gamma^{2}+\gamma-2 \phi-2\right)\right]-\left(\gamma^{2}+\gamma-2 \phi-2\right) \leq 0 .
$$

Setting $x=\left(\gamma^{2}+\gamma-2 \phi-2\right)$ will make the expression negative since $\left(\gamma^{2}+\gamma-2 \phi-2\right)>0$. On the other hand, letting $x \rightarrow \infty$ makes the expression positive. 


\subsection{Proof of proposition 11}

Proof. Inserting the expressions for $W^{N}$ and $W^{P}$ yields

$$
\begin{aligned}
n_{A} p s-n_{A} \frac{c}{2}(\gamma+1)^{2}-n_{B} \frac{c}{2}-n_{C} \frac{c}{2} \phi^{2} & \geq n_{A} p s-n_{B} \frac{1}{2} \frac{p s}{\gamma(\gamma+1)}-n_{A} \frac{1}{2} \frac{\gamma p s}{(\gamma+1)} \\
n_{A} \frac{c}{2}\left(\gamma^{2}+2 \gamma+1\right)+n_{B} \frac{c}{2}+n_{C} \frac{c}{2} \phi^{2} & \leq n_{A} \frac{1}{2} \frac{p s}{(\gamma+1)}+n_{A} \frac{1}{2} \frac{\gamma p s}{(\gamma+1)} \\
n_{C}\left[\phi \frac{c}{2}\left(\gamma^{2}+2 \gamma+1\right)+\gamma \phi \frac{c}{2}+\frac{c}{2} \phi^{2}\right] & \leq n_{C} \phi \frac{p s}{2} \\
\gamma^{2}+3 \gamma+\phi+1 & \leq \frac{p s}{c} .
\end{aligned}
$$

\section{References}

[1] Alesina, A. (1988). Credibility and Policy Convergence in a Two-party System with Rational Voters. American Economic Review 78, 796-805.

[2] Alesina, A.; Spear, S.E. (1988): An Overlapping Generations Model of Electoral Competition. Journal of Public Economics 37, 359-379.

[3] Armstrong, M. (2004): Competition in Two-Sided Markets. University College London. Mimeo.

[4] Baye, M.; Kovenock, D.; de Vries, C. (1993): Rigging the Lobbying Process: An Application of the All-Pay Auction. American Economic Review 86, 289-294.

[5] Bernheim, B.D.; Whinston, M.D. (1986): Menu Auctions, Resource Allocation, and Economic Influence. Quarterly Journal of Economics 101, 1-32.

[6] Besley, T.; Coate, S. (1997): An Economic Model of Representative Democracy. Quarterly Journal of Economics 112, 85-114.

[7] Besley and Coate (2001): Lobbying and Welfare in Representative Democracy. Review of Economic Studies 68, 67-82.

[8] Caillaud, B.; Tirole J. (2002): Parties as Political Intermediaries. Quarterly Journal of Economics 117, 1453-1491.

[9] Encyclopedia of Austria (2005): http://www.aeiou.at/aeiou.encyclop.p/ p605828.htm;internal\&action = _setlanguage.action?LANGUAGE $=$ en

[10] Grossman, G.M.; Helpman, E. (1994): Protection for Sale. American Economic Review $84,833-850$.

[11] Felli, L.; Merlo A. (2006): Endogenous Lobbying. Journal of the European Economic Association. Forthcoming. 
[12] Helpman, E.; Persson T. (2001): Lobbying and Legislative Bargaining. Advances in Economic Analysis \& Policy 1, article 3.

[13] Jackson, M.O.; Wolinsky, A. (1996): A Strategic Model of Social and Economic Networks. Journal of Economic Theory 71,44-74.

[14] Mair, P.; van Biezen, I. (2001): Party Membership in Twenty European Democracies, 1980-2000. Party Politics 7, 5-21.

[15] OECD (2001): OECD Public Management Service. <http://www.oecd.org/dataoecd/26/51/1826995.xls>

[16] OECD (2005): Labour Force Statistics. <http://www.oecd.org/dataoecd/62/38/35267227.pdf>

[17] Osborne, M.J.; Slivinski, A. (1996): A Model of Political Competition with Citizen Candidates. Quarterly Journal of Economics 111, 65-96.

[18] Persson, T.; Tabellini, G. (2003): The Economic Effect of Constitutions. MIT Press: Cambridge.

[19] Rochet, J-J.; Tirole J. (2003): Platform Competition in Two-Sided Markets. Journal of the European Economic Association, 1(4), 990-1029.

[20] Rochet, J-J.; Tirole J. (2004): Two-Sided Markets - An Overview. IDEI. Working Paper. Toulouse.

[21] Rubinstein, A.; Wolinsky A. (1987): Middlemen. Quarterly Journal of Economics. 102(3), 581-594.

[22] Statistics Finland. (2005): Tables 14 and 17 at http://www.tilastokeskus.fi/tup/maanum/taulukot_en.html

[23] Tullock, G. (1967): The Welfare Costs of Tariffs, Monopolies and Theft. Western Economic Journal 5, 224-232.

[24] Tullock, G. (1980): Efficient Rent-Seeking. In J.M. Buchanan, R. Tollison and G. Tullock (eds), Toward a Theory of the Rent Seeking Society. Texas A\&M Press. pp267-292. 